\title{
An evaluation of the SAGE III version 4 aerosol extinction coefficient and water vapor data products
}

\author{
L. W. Thomason ${ }^{1}$, J. R. Moore $^{2}$, M. C. Pitts ${ }^{1}$, J. M. Zawodny ${ }^{1}$, and E. W. Chiou ${ }^{3}$ \\ ${ }^{1}$ NASA Langley Research Center, Hampton, Virginia, USA \\ ${ }^{2}$ Science Systems and Applications, Inc., Hampton, Virginia, USA \\ ${ }^{3}$ ADNET Systems Inc., Lanham, Maryland, USA
}

Received: 12 June 2009 - Published in Atmos. Chem. Phys. Discuss.: 21 October 2009

Revised: 16 February 2010 - Accepted: 18 February 2010 - Published: 1 March 2010

\begin{abstract}
Herein, we provide an assessment of the data quality of Stratospheric Aerosol and Gas Experiment (SAGE III) Version 4 aerosol extinction coefficient and water vapor data products. The evaluation is based on comparisons with data from four instruments: SAGE II, the Polar Ozone and Aerosol Measurement (POAM III), the Halogen Occultation Experiment (HALOE), and the Microwave Limb Sounder (MLS). Since only about half of the SAGE III channels have a direct comparison with measurements by other instruments, we have employed some empirical techniques to evaluate measurements at some wavelengths. We find that the aerosol extinction coefficient measurements at 449, 520, 755,869 , and $1021 \mathrm{~nm}$ are reliable with accuracies and precisions on the order of $10 \%$ in the mission's primary aerosol target range of 15 to $25 \mathrm{~km}$. We also believe this to be true of the aerosol measurements at $1545 \mathrm{~nm}$ though we cannot exclude some positive bias below $15 \mathrm{~km}$. We recommend use of the $385 \mathrm{~nm}$ measurements above $16 \mathrm{~km}$ where the accuracy is on par with other aerosol channels. The $601 \mathrm{~nm}$ measurement is much noisier $(\sim 20 \%)$ than other channels and we suggest caution in the use of these data. We believe that the $676 \mathrm{~nm}$ data are clearly defective particularly above $20 \mathrm{~km}$ (accuracy as poor as 50\%) and the precision is also low $(\sim 30 \%)$. We suggest excluding this channel under most circumstances. The SAGE III Version 4 water vapor data product appears to be high quality and is recommended for science applications in the stratosphere below $45 \mathrm{~km}$. In this altitude range, the mean differences with all four corroborative data sets are no bigger than $15 \%$ and often less than $10 \%$ with exceptional agreement with POAM III and MLS. Above $45 \mathrm{~km}$, it seems likely that SAGE III water vapor values are increasingly too large and should be used cautiously or avoided. We believe that SAGE III meets its preflight goal
\end{abstract}

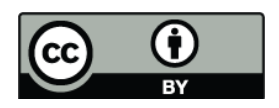

Correspondence to: $\mathrm{L}$. W. Thomason (l.w.thomason@nasa.gov) of $15 \%$ accuracy and $10 \%$ precision between 15 and $45 \mathrm{~km}$. SAGE III water vapor data does not appear to be affected by aerosol loading in the stratosphere.

\section{Introduction}

The Stratospheric Aerosol and Gas Experiment (SAGE III) continues the long SAGE series of solar occultation instruments (SAGE, 1979-1981; SAGE II, 1984-2005) that produce high vertical resolution ozone and multi-wavelength stratospheric aerosol extinction coefficient profiles. In combination with other satellite (e.g., the Halogen Occultation Experiment) and in situ instruments (e.g., ozonesondes), the SAGE series has provided crucial observations in understanding global ozone trends (WMO, 2003) and the impact of volcanoes and human activities on stratospheric aerosol levels (SPARC, 2006).

Like its predecessors, SAGE III measures line-of-sight transmission profiles through the limb of the Earth's atmosphere using the Sun as the radiant source. Due to the orbit of the Meteor 3M platform, SAGE III profiles are restricted to bands in the Northern and Southern Hemispheres. In the north, observations are made near $80^{\circ} \mathrm{N}$ in March and November, near $65^{\circ} \mathrm{N}$ in January, and near $40^{\circ} \mathrm{N}$ in July. In the Southern Hemisphere, observations are made near $30^{\circ} \mathrm{S}$ in January and near $60^{\circ} \mathrm{S}$ in July. The multispectral transmission profiles are used to retrieve vertical profiles of the molecular density of ozone and $\mathrm{NO}_{2}$, water vapor mixing ratio, and aerosol extinction coefficient at 9 wavelengths between 384 and $1545 \mathrm{~nm}$ (Table 1). The first public release of SAGE III solar occultation data (Version 2) took place in December 2002 followed by the release of Version 3 in April 2004. The quality of aerosol extinction coefficient data in these versions was reported by Thomason and Taha (2003) and Thomason et al. (2007). The utility of the multispectral extinction coefficient data set was established by Poole et

Published by Copernicus Publications on behalf of the European Geosciences Union. 
Table 1. SAGE III aerosol extinction coefficient channel locations, width, and validation source: POAM III (PIII), SAGE II (SII), spectral ratio (SR), and interpolation (I).

\begin{tabular}{llll}
\hline $\begin{array}{l}\text { Central } \\
\text { Wavelength }(\mathrm{nm})\end{array}$ & $\begin{array}{l}\text { Number of } \\
\text { pixels }\end{array}$ & $\begin{array}{l}\text { FWHM } \\
(\mathrm{nm})\end{array}$ & $\begin{array}{l}\text { Validation } \\
\text { Source }\end{array}$ \\
\hline 384.5 & 5 & 6.1 & PIII(353), SII(385), SR \\
448.5 & 4 & 5.2 & PIII(442), SII(452) \\
520.3 & 5 & 6.1 & SII(525) \\
601.2 & 3 & 4.3 & I,PIII(601) \\
675.6 & 5 & 6.1 & I \\
755.4 & 5 & 6.0 & I,PIII(779) \\
869.3 & 5 & 6.2 & I \\
1021.6 & 6 & 7.8 & PIII(1018), SII(1020) \\
1545.2 & filter & 29.8 & SR \\
\hline
\end{tabular}

al. (2003) who demonstrated the ability to infer some microphysical properties of polar stratospheric clouds. Ozone data quality for Version 3 was reported by Wang et al. (2006). Water vapor was not included in either Version 2 or 3. SAGE III can also operate in a lunar occultation mode that uses the Moon as the radiant source or the illuminated atmosphere in limb scatter mode. Rault (2005) and Rault and Taha (2007) discuss the limb scatter retrieval process and ozone data quality, respectively. An evaluation of SAGE III Version 3 lunar occultation ozone, $\mathrm{NO}_{2}$, and $\mathrm{NO}_{3}$ data products can be found in Wang et al. (2009).

In June 2008, Version 4 SAGE III data products were released including the initial release of a water vapor data product. Herein, we evaluate the aerosol extinction coefficients and water vapor data products through comparison with independent data sets from other spaceborne instruments and, in the case of the aerosol product, internal self-consistency. Version 4 ozone and $\mathrm{NO}_{2}$ data products are evaluated in a separate document (Wang et al., 2009). Lunar occultation does not include aerosol or water vapor data products and therefore is not discussed in this paper.

\subsection{The SAGE III mission}

SAGE III was launched in December 2001 aboard the Russian METEOR 3M spacecraft. Data was acquired from the instrument from February 2002 until the end of the spacecraft mission in March 2006. As an intermediate solar occultation product, line-of-sight (LOS) transmission profiles from 0.5 to $100 \mathrm{~km}$ at 87 wavelengths distributed from the ultraviolet to the near infrared are computed by dividing observed throughthe-atmosphere brightness by values measured on paths (tangent heights $>100 \mathrm{~km}$ ) that are not affected by atmospheric attenuation $\left(\mathrm{I}_{o}\right)$. The transmission profiles are produced on a $0.5-\mathrm{km}$ grid with an estimated $0.7 \mathrm{~km}$ vertical resolution (SAGE III ATDB, 2002). The ensemble of LOS transmission profiles is used to produce vertical profiles of ozone, $\mathrm{NO}_{2}$, and water vapor as well as aerosol extinction coefficient at nine wavelengths. Due to orbital considerations, spacecraft sunset profiles were made between $45^{\circ} \mathrm{N}$ (June) and $80^{\circ} \mathrm{N}$ (February/October) while spacecraft sunrise events occurred between $30^{\circ} \mathrm{S}$ (January) and $60^{\circ} \mathrm{S}$ (May). All events in the Southern Hemisphere are astronomical sunsets. In the Northern Hemisphere, the events are astronomical sunsets as well except during winter where the spacecraft sunset events occurred during astronomical sunrise.

\subsection{The aerosol extinction coefficient product}

Aerosol extinction does not have an independent retrieval algorithm but is instead a by-product of the retrieval of ozone and $\mathrm{NO}_{2}$ (SAGE III ATDB, 2002). We report aerosol extinction at 9 wavelengths distributed fairly evenly between 385 and $1545 \mathrm{~nm}$ as shown in Table 1. Aerosol "channels" are produced by averaging the LOS transmission from 4 or more adjacent pixels in the detector array except at $1545 \mathrm{~nm}$ where the channel is measured in the zero-order of the spectrometer using a filter and a single InGaAs detector. At each of the 9 channels, aerosol extinction is derived by removing the effects of molecular scattering, ozone absorption (particularly for channel wavelengths at and less than $755 \mathrm{~nm}$ ), and $\mathrm{NO}_{2}$ absorption (particularly for channel wavelengths at and less than $601 \mathrm{~nm}$ ). The molecular density is derived from the Global Modeling and Assimilation Office (GMAO) meteorological analyses (Bloom et al., 2005) while ozone and $\mathrm{NO}_{2}$ are derived from multi-linear regression using 19 individual pixel channels between 433 and $450 \mathrm{~nm}\left(\mathrm{NO}_{2}\right)$ and 10 3-pixel average channels between 562 and $621 \mathrm{~nm}$ (ozone). The precision and accuracy of the aerosol product is tied to the measurement noise in the channel, the quality of the GMAO density product, the noise and bias in the retrieved ozone and $\mathrm{NO}_{2}$, and the consistency of the cross sections used in the ozone/ $\mathrm{NO}_{2}$ multi-linear regression retrieval and those at the aerosol channel wavelengths. While this latter condition is not immediately obvious, it is nonetheless important. For instance, in Version 3 we found that the $755 \mathrm{~nm}$ aerosol extinction exhibited anomalous extinction that was strongly correlated to the concomitant ozone number density (Thomason and Taha, 2003) and suggested a cross section error of about $10 \%$ at $755 \mathrm{~nm}$ relative to the center of the Chappuis ozone band. In Version 4, this issue was mitigated by replacing the ozone cross sections of Shettle and Anderson et al. (1994) and Burkholder and Talukdar (1994) with those reported by Bogumil et al. (2003). This data set has the advantage of having been measured throughout the SAGE III measurement wavelength range using a single consistent instrument. Since aerosol loading throughout the SAGE III lifetime is very low, there remains the potential for small anomalies in the aerosol extinction coefficient product related to inhomogeneity in the quality of the cross section data particularly at wavelengths where the ozone cross sections are small but ozone absorption still significantly contributes to the total optical depth (e.g., altitudes above $25 \mathrm{~km}$ ). It 
is also important to keep in mind that while the individual aerosol extinction coefficient channels are not completely independent from the others, no functional form for aerosol extinction variation with wavelength is imposed on the aerosol spectra. The target precision and accuracy for long wavelength aerosol extinction coefficient profiles were $5 \%$ from 0 to $40 \mathrm{~km}$ (SAGE III ATDB, 2002).

\subsection{The water vapor product}

The SAGE III water vapor absorption band (referred to as the $\rho \sigma \tau$ band) is relatively weak in the stratosphere and the peak absorption for the band at SAGE III resolution excluding interfering species is only about $1 \%$ for a limb observation with a tangent altitude near the tropopause. As a result, water vapor retrievals using this band are challenging. The SAGE II water vapor product was primarily dependent on a single $\sim 30$-nm wide channel located in the $\rho \sigma \tau$ water vapor absorption band. This product has well known data quality issues due to the combination of the weak band strength, the need to account for an apparent drift in the 940-nm channel spectral response as well as the precision required to clear aerosol and ozone effects (Thomason et al., 2004). Removing aerosol effects ("clearing") is dependent on interpolating between relatively widely spaced aerosol extinction measurements at 525 and $1020 \mathrm{~nm}$.

For SAGE III, a conscious effort was made to mitigate issues that had a deleterious impact on SAGE II water vapor data quality. For instance, the nominal water vapor measurement employs 28 individual pixels (or channels) on the spectrometer's CCD (charge-coupled device) detector that cover the wavelength range from 933 to $958 \mathrm{~nm}$ or nearly spanning the $\rho \sigma \tau$ water vapor absorption band. The channels are spaced $\sim 1.0 \mathrm{~nm}$ apart and the full width-half maximum (FWHM) for the individual channels is $1.2 \mathrm{~nm}$ and the measurement precision is close to $0.1 \%$. As a part of the routine data processing scheme, a spectral calibration is performed during each sunrise and sunset encountered by the spacecraft. Using this capability, we found that the in-flight calibration was shifted relative to the ground-based calibration by about $0.4 \mathrm{~nm}$. While it was possible to use a unique spectral calibration for each event, in practice minimal movement of the channel locations was observed during the SAGE III mission and a single calibration is used in data processing.

Prior to Version 4, the basic water vapor retrieval algorithm removed aerosol contributions in the water vapor channels by interpolating from nearby aerosol channels (e.g., 755, 869 , and $1021 \mathrm{~nm}$ ) and removed ozone using the value inferred from the Chappuis band centered $600 \mathrm{~nm}$. This is similar to that used in the SAGE II retrieval method (Thomason et al., 2004). The residual optical depth is then used to infer a profile of water vapor mixing ratio using a global fit approach similar to the method described by Marquardt (1963). We felt that the abundance of aerosol channels around the water vapor feature (particularly those at 755,869 , and $1021 \mathrm{~nm}$ )
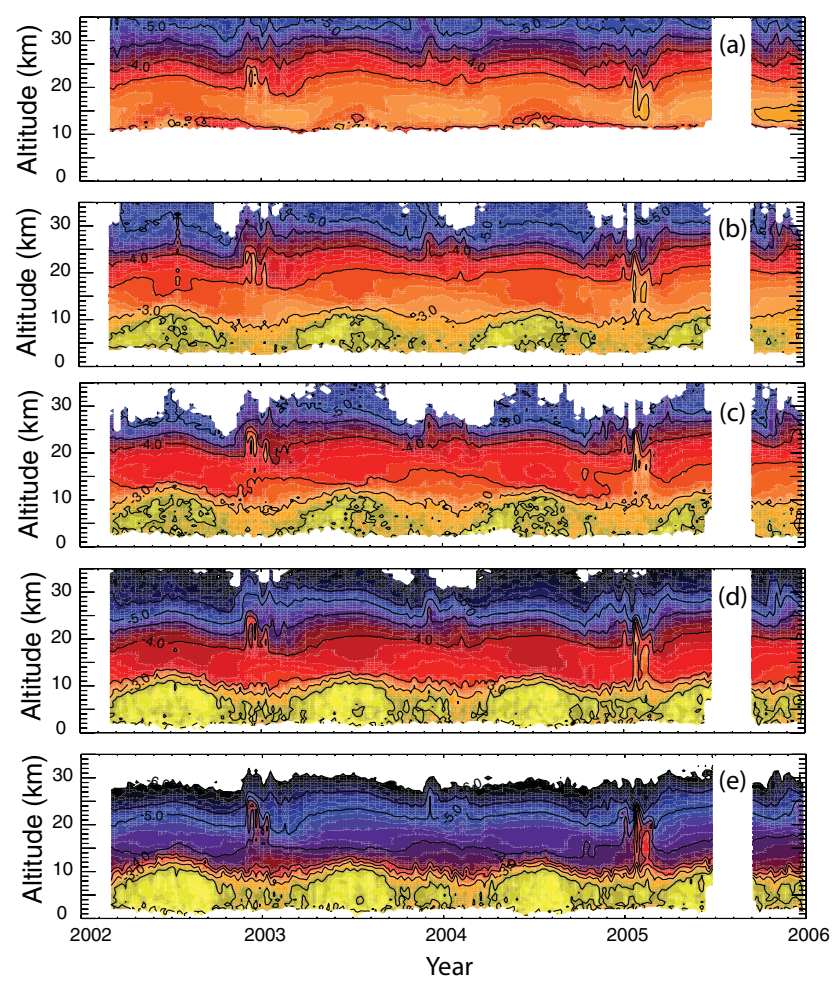

Fig. 1. SAGE III aerosol extinction coefficient at 385 (a), 520 (b), 676 (c), 869 (d), and $1545 \mathrm{~nm}$ (e) from February 2002 to December 2005 in bins of 0.02 years by $0.5 \mathrm{~km}$ requiring at least 5 data points per bin. Isopleths of extinction coefficient $(1 / \mathrm{km})$ are given every 0.5 cycles of log base 10 ; color contours are given every 0.1 cycles of $\log$ base 10. The lowest values of extinction coefficient are shown as dark blue and the largest values are shown as yellow.

would be more than adequate to estimate aerosol extinction in the water vapor channels. The target precision and accuracy for water vapor were 15 and $10 \%$ from 5 to $50 \mathrm{~km}$ (SAGE III ATDB, 2002). Unfortunately, we found that both version 2 and 3 water vapor products were of considerably lower quality than expectation and were therefore not released to the public. Changes in the Version 4 processing, particularly decreasing noise in the LOS transmission and improved ozone cross sections, have produced a water vapor data product that is close to preflight expectations and allow its release in this version.

\section{Aerosol extinction coefficient evaluation}

Figure 1 shows a subset of SAGE III aerosol extinction coefficient channels $(385,520,676,869$, and $1545 \mathrm{~nm})$ depicting aerosol variation in Northern Hemisphere from February 2002 through December 2005. The plots are characteristic of a relatively quiescent period with no large volcanic events during this period. The variations are primarily driven by the slow variations in the latitude and season of these 
measurements, seasonally dependent transport from low latitudes, and by occurrence of polar stratospheric clouds (PSCs) in the winter. For instance, the strong gradient between the clean stratosphere and the hazier troposphere moves from around $12 \mathrm{~km}$ in the summertime mid-latitudes to around $7 \mathrm{~km}$ during the Arctic winter, essentially tracking the change in the height of the tropopause. PSCs are observed in all three winters though vary substantially from year to year.

Aerosol validation is difficult because there is no standard measurement with which to compare. All occultation instruments have historically validated aerosol data by comparing with each other and a handful of other space-based instruments (e.g, the Improved Limb Atmospheric Sounder (ILAS) II). For SAGE III, a number of aerosol extinction channels have no corresponding measurement from any other instrument. Validation with other kinds of instruments is equally problematic. Lidar is possibly useful for heavily loaded periods but for the SAGE III lifetime, stratospheric aerosol levels were at historic lows and corresponding lidar backscatter ratios were often less than 1.04 (only $4 \%$ of the signal comes from aerosol) and converting from a backscatter measurement to extinction is not trivial considering the level of precision/accuracy required for validation. Similarly the Stratospheric Processes and their Role in Climate (SPARC) Assessment of Stratospheric Aerosol Properties (SPARC, 2006) demonstrated that the University of Wyoming Optical Particle Counter (the OPC whose extensive data set spans the entire space-based data set) cannot be reliably used to produce useful aerosol extinction coefficient measurements particularly at long wavelengths during low loading periods. As a result, our ability to validate SAGE III aerosol extinction coefficient data at the target accuracy and precisions (5\%/5\%) is limited. We have used a variety of methods for the evaluation for the 9 channels. This includes measurement spacebased instrument comparisons (SAGE II and POAM III) at 385, 449, 520, 601, 755 and $1021 \mathrm{~nm}$ and comparisons internal to SAGE III (effectively consistency tests) at 385, 601, 755,869 , and $1545 \mathrm{~nm}$. We included internal tests at 385 , 601 , and 755 due to some concerns about the quality of the data available from other instruments at those wavelengths.

To match events with SAGE II and POAM III, we have used the criteria used in Thomason et al. (2007) and similar to those used in other comparisons (e.g., Randall et al., 2001). This defined a coincidence at a given altitude for events within \pm 1 day, $\pm 24^{\circ}$ longitude, and $\pm 5 \%$ of the potential vorticity (PV) range observed in the SAGE III Northern Hemisphere data. The PV value is very roughly the equivalent of a $2^{\circ}$ range in latitude. $\mathrm{PV}$ is a dynamical tracer and is more useful than latitude for matching event locations since it can better characterize the air mass in which the measurements were made particularly in the presence of strong PV and species gradients across the edge of the wintertime polar vortex. We have found that using PV substantially reduces the variance with little impact on the mean in matched data sets. SAGE III and SAGE II auxiliary data sets which contain
PV and other dynamical information have been produced by Gloria Manney (Manney et al., 2001) using National Centers for Environmental Prediction (NCEP) analyses and are available at ftp://mls.jpl.nasa.gov/pub/outgoing/manney. PV is included as a part of the POAM III data files. We find a handful of coincidences by these criteria where the latitude difference approaches $10^{\circ}$ and including these points notably increases the standard deviation of the comparisons. As a result, we include a limit of a $4^{\circ}$ difference in latitude. We also eliminated all coincidences where relative errors are greater than $75 \%$. The value used for the relative error limit makes virtually no difference in the quality and quantity of matches except above $22 \mathrm{~km}$ where significant numbers of POAM III events are eliminated by a criterion more restrictive than that required by the SAGE instruments. As reported by Lumpe et al. (2002) POAM III extinction measurements report significantly larger uncertainties, particularly at $1018 \mathrm{~nm}$, than those reported to be associated with either SAGE data set.

Following Thomason et al. (2007), for matched events the mean and standard deviation are computed based on the ratio of individual matched pairs rather than absolute extinction values. We perform our statistical averaging on the ratio, $r$, of the data pairs as given by

$r=\frac{k_{\mathrm{SAGE}} \mathrm{III}(\lambda)}{k_{i}(\lambda)}$

where $k_{\text {SAGE III }}(\lambda)$ is the aerosol extinction coefficient for SAGE III and $k_{i}(\lambda)$ is the corresponding aerosol extinction coefficient at wavelength $\lambda$ for either SAGE II or POAM III. Since the dynamic range of observed extinction at a given altitude is between a factor of 3 and 10, there is a tendency for the largest extinction pairs to dominate the statistical comparison when absolute extinction is used. However, the performance at smaller values is often a better measure of the robustness of the measurements and, therefore, of at least equal importance in evaluating the SAGE III aerosol extinction coefficient product. Performing statistics on the ratios (or percentage differences) gives equal weight to large and small values. An additional factor to note in the following comparisons is that some differences between channel pairs can result from the small wavelength differences in the channel pair locations. For example, the angstrom coefficient for the observed stratospheric aerosol extinction coefficient spectra is typically between 0 and 2 . As a result, the difference between the SAGE III/II $449 \mathrm{~nm} / 452 \mathrm{~nm}$ pair should be between 0 and $+1.5 \%$ while for the SAGE III/POAM III (442 nm) pair it should be between -3 and $0 \%$. Other matching pairs (Table 1) with noteworthy wavelength differences include the POAM III/SAGE III pairs at 353/385 nm (an 8\% wavelength difference) and $779 / 755 \mathrm{~nm}$ (a $3 \%$ difference). These differences are not accounted for in the comparisons shown in this document. 

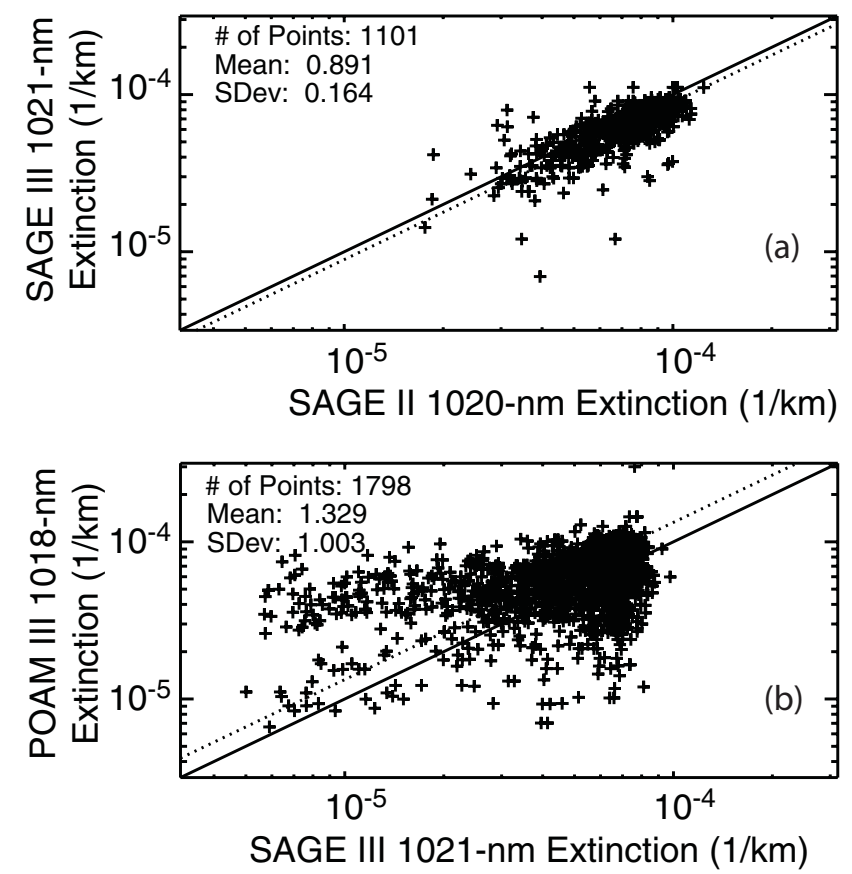

Fig. 2. Comparison of coincident pairs at $20 \mathrm{~km}$ for SAGE III version 4 1020-nm aerosol extinction coefficients with data from SAGE II (a) and POAM III (b). For frame (a), a total of 1101 matched points were used with a mean of 0.891 and a standard deviation of 0.164 . For frame (b), the number of points used is 1798 with a mean of 1.329 with a standard deviation of 1.003 .

\subsection{Comparisons with SAGE II and POAM III}

For most channel pairs and altitudes, we found about 1100 SAGE II/III matched pairs and about 1800 for POAM III/SAGE III. Figure 2 shows results for the comparison of SAGE II 1020-nm and POAM III 1018-nm aerosol extinction coefficient with that for $1021 \mathrm{~nm}$ for SAGE III at $20 \mathrm{~km}$. For this wavelength, the results shown in Fig. 2 are typical of all altitudes; the SAGE II/III comparisons (Fig. 2a) show a difference of about $10 \%$ (SAGE III smaller) with a standard deviation of about $15 \%$ and a correlation of 0.76 . For the POAM III and SAGE III comparisons (Fig. 2b), we observe differences of about $30 \%$ (SAGE III smaller) with a standard deviation of near $100 \%$ and a correlation of 0.41 . The POAM III/SAGE III comparisons show more variation with altitude than for SAGE III/II comparisons). The large differences and standard deviation are driven by relatively large noise throughout the dynamic range of measurements and a systematic difference when the SAGE III extinction coefficient is less than $2 \times 10^{-5} \mathrm{~km}^{-1}$. The apparent bias at low aerosol extinction is primarily driven by events occurring within the Arctic vortex (where matches with SAGE II are unfortunately sparse). Within the vortex, SAGE III typically reports low extinction at all wavelengths which is consistent with observations reported by Kent et al. (1985) and Thomason and Poole (1994) using Stratospheric Aerosol Measure-
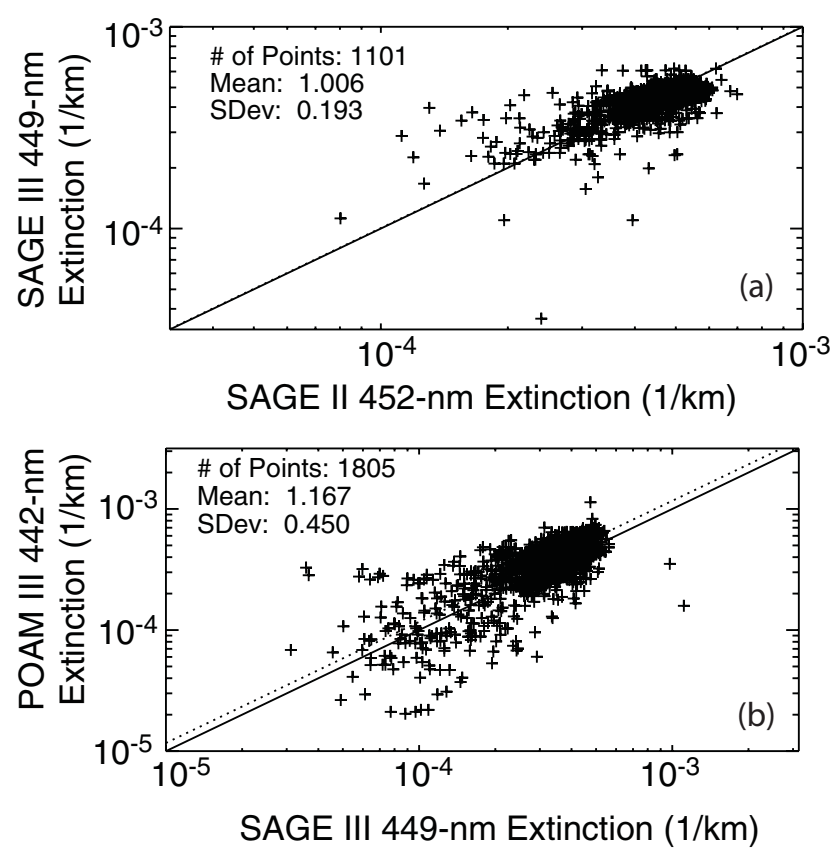

Fig. 3. Comparison of coincident pairs at $20 \mathrm{~km}$ for SAGE III Version 4 449-nm aerosol extinction coefficients with data from SAGE II at $452 \mathrm{~nm}$ (a) and POAM III at $442 \mathrm{~nm}$ (b). For frame (a), 1101 matched points were used with a mean of 1.006 and a standard deviation of 0.193 . For frame (b), 1805 points were used with a mean of 1.167 and a standard deviation of 0.450 .

ment (SAM II) and SAGE II data. POAM III shows a less pronounced aerosol extinction reduction at this wavelength though it is not clear how much the noise in this channel is masking otherwise more typical results. Figure 3 shows the matching comparison at $449 \mathrm{~nm}$. In this case, the comparisons of the SAGE III $449 \mathrm{~nm}$ extinction coefficient with SAGE II (452 nm) and POAM III (442 nm) show a more consistent behavior across the extinction coefficient range observed by the instruments. The bulk statistics show that SAGE III extinction coefficient at $20 \mathrm{~km}$ is very close to SAGE II values $(+0.6 \%)$ with a standard deviation of $19.3 \%$ and correlation of 0.66 ; relative to POAM III, the mean difference is $-16.7 \%$ with a standard deviation of $45.0 \%$ and correlation of 0.75 . Unlike at $1021 \mathrm{~nm}$, the SAGE III and POAM III agreement at $449 \mathrm{~nm}$ is not a strong function of extinction. At $1021 \mathrm{~nm}$ under the low aerosol levels observed during the entire SAGE III mission, the fraction of the total LOS signal coming from aerosol is about $50 \%$ from the tropopause to $25 \mathrm{~km}$ (Thomason et al., 2008) and, as a result, good agreement between the three instruments is expected. On the other hand, at $449 \mathrm{~nm}$ the fraction of the signal from aerosol is less than $10 \%$ and therefore a more challenging measurement.

Figure 4 summarizes the comparison of SAGE III aerosol extinction coefficient at the 6 wavelengths where either SAGE II and/or POAM III extinction measurements are 

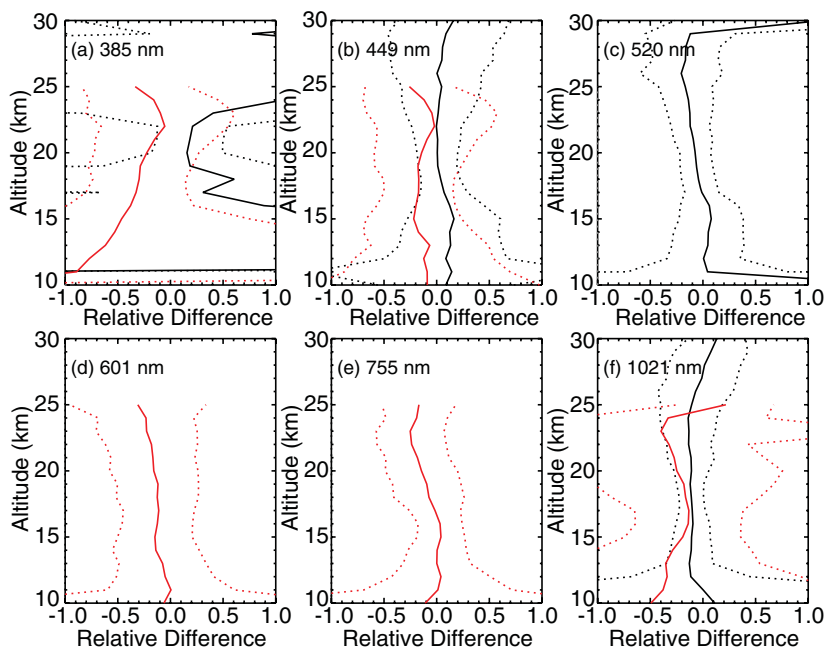

Fig. 4. Profile of the mean difference between comparisons of SAGE III version 4 aerosol extinction coefficient at $385 \mathrm{~nm}$ (a), 449 (b), 520 (c), 601 (d), 755 (e), and $1021 \mathrm{~nm}$ (f) with spectrally close channels from SAGE II (black) and POAM III (red) as solid lines. The dotted lines show the range defined by 1 standard deviation $( \pm 1-\sigma)$.

available. There are three SAGE III channels for which there are nearby (spectrally) measurements from POAM III and SAGE II: 385,449 , and $1021 \mathrm{~nm}$. The 1021-nm comparison is particularly important since it is where we nominally expect the measurements to be most robust and spacebased measurements at this wavelength have an extensive history that dates back to the Stratospheric Aerosol Measurement (SAM) II (1978-1991) and original SAGE instrument (1979-1981). For SAGE III/SAGE II, we find (Fig. 4f) that the difference is nearly constant at about $-10 \%$ from 12 to $25 \mathrm{~km}$ with a tilt toward positive values outside of that range. The standard deviation is a minimum at $18 \mathrm{~km} \mathrm{(11 \% )} \mathrm{and} \mathrm{in-}$ creases to a maximum of $35 \%$ at $28 \mathrm{~km}$ while correlations vary from 0.6 at $10 \mathrm{~km}$ to a peak of 0.82 at $22 \mathrm{~km}$ to near 0.0 at $30 \mathrm{~km}$. These results are somewhat better than those for earlier versions as reported in Thomason and Taha (2003) and Thomason et al. (2007). For POAM III, the agreement varies from $15 \%$ at $17 \mathrm{~km}$ to more than $40 \%$ below $15 \mathrm{~km}$ and above $21 \mathrm{~km}$. The standard deviation for this set is never less than $50 \%$ and often greater than $100 \%$. The 449-nm aerosol extinction set show outstanding agreement and are nearly indistinguishable (Fig. 4b). For SAGE III/SAGE II the difference is again fairly consistent with altitude and less than $10 \%$ from 15 to $29 \mathrm{~km}$ and often only a few percent (19-27 km). The standard deviation is around $30 \%$ from 12 to $23 \mathrm{~km}$ and slowly increases to $50 \%$ at $30 \mathrm{~km}$ while the correlation is between 0.5 and 0.8. For POAM III/SAGE III comparisons, there is a little more structure in the difference profile where it is within $\pm 10 \%$ from 18 to $24 \mathrm{~km}$ and is not worse than $25 \%$ over the entire profile. The standard deviation is be- tween 30 and $50 \%$ (above $14 \mathrm{~km}$ ) and the correlation is between 0.4 and 0.75 above $14 \mathrm{~km}$.

Aerosol extinction measurements around $385 \mathrm{~nm}$ are particularly difficult due to the substantial molecular scattering contribution to the total LOS optical depth and the LOS optical depths are typically noisy because the solar disk is more structured at short wavelengths than in the visible due to the increased contrast of the solar granules. As a result, we do not recommend using aerosol at this wavelength below $15 \mathrm{~km}$ though it is reported to the lowest altitude available $(\sim 10 \mathrm{~km})$. The $385 \mathrm{~nm}$ channel is a weak member of the SAGE II aerosol extinction coefficient ensemble and is not used in any aspect of the SAGE II data processing (e.g., ozone retrieval) (SPARC, 2006) and so is not a robust tool by which to evaluate the SAGE III measurement. For SAGE III/II comparisons, we observe (Fig. 4a) a bias of 20 to $30 \%$ from 16 to $23 \mathrm{~km}$ with much larger values outside of this range and a standard deviation from $30 \%$ (at $21 \mathrm{~km}$ ) to much greater than $100 \%$ outside the favorable range. If we restrict the comparisons to extinction coefficient greater than $10^{-4} / \mathrm{km}$ we find that the comparison is much better with a mean difference of $\sim 10 \%$ between 17 and $29 \mathrm{~km}$ and a variance of about $20 \%$. This matches our previous observations of SAGE II $385 \mathrm{~nm}$ extinction coefficient in that this channel is better at large extinctions and above $15 \mathrm{~km}$ (e.g., SPARC, 2006). Unfortunately, this comparison is not a useful measure of SAGE III $385 \mathrm{~nm}$ extinction coefficient data quality. For SAGE III/POAM III comparisons, we find an agreement better than $20 \%$ above $20 \mathrm{~km}$ (POAM III greater than SAGE III) that increases at lower altitudes to $50 \%$ at $15 \mathrm{~km}$ and the standard deviation is fairly constant at about $50 \%$. Some of the difference for this pair can be attributed to the wavelength difference $(8 \%)$ and so the comparison above $20 \mathrm{~km}$ is good. On the other hand, the consistent slope to larger differences below $20 \mathrm{~km}$ is more difficult to understand.

There are 3 wavelengths with a single comparison pair: $520 \mathrm{~nm}$ with SAGE III/II and 601 and $755 \mathrm{~nm}$ for SAGE III/POAM III. For the $520 \mathrm{~nm}$ pair, (Fig. 4c) we find that SAGE II and SAGE III are within $10 \%$ from 11 to $23 \mathrm{~km}$ and with $20 \%$ between 23 and $29 \mathrm{~km}$ with a standard deviation of 15 to $30 \%$ over this altitude range. At $601 \mathrm{~nm}$, both aerosol channels are strongly influenced by ozone absorption and generally expectations for these aerosol channels are low. Nonetheless we find a reasonably well behaved comparison between these two channels. As shown in Fig. $4 d$, the mean difference runs from near 0 at $10 \mathrm{~km}$ to about $30 \%$ (SAGE III less than POAM III) with a systematic tilt in the profile shape and a standard deviation of about $30 \%$ over the extent of the profile. Finally at $755 \mathrm{~nm}$ (compared to POAM III at $779 \mathrm{~nm}$ ), we find a difference (Fig. 4e) less than $5 \%$ below $17 \mathrm{~km}$ with a tilt toward a difference of $30 \%$ at $23 \mathrm{~km}$ with SAGE III less than POAM III. Nominally, we would expect SAGE III extinction at $755 \mathrm{~nm}$ to be greater than POAM III at $779 \mathrm{~nm}$ but we observe the opposite. This 

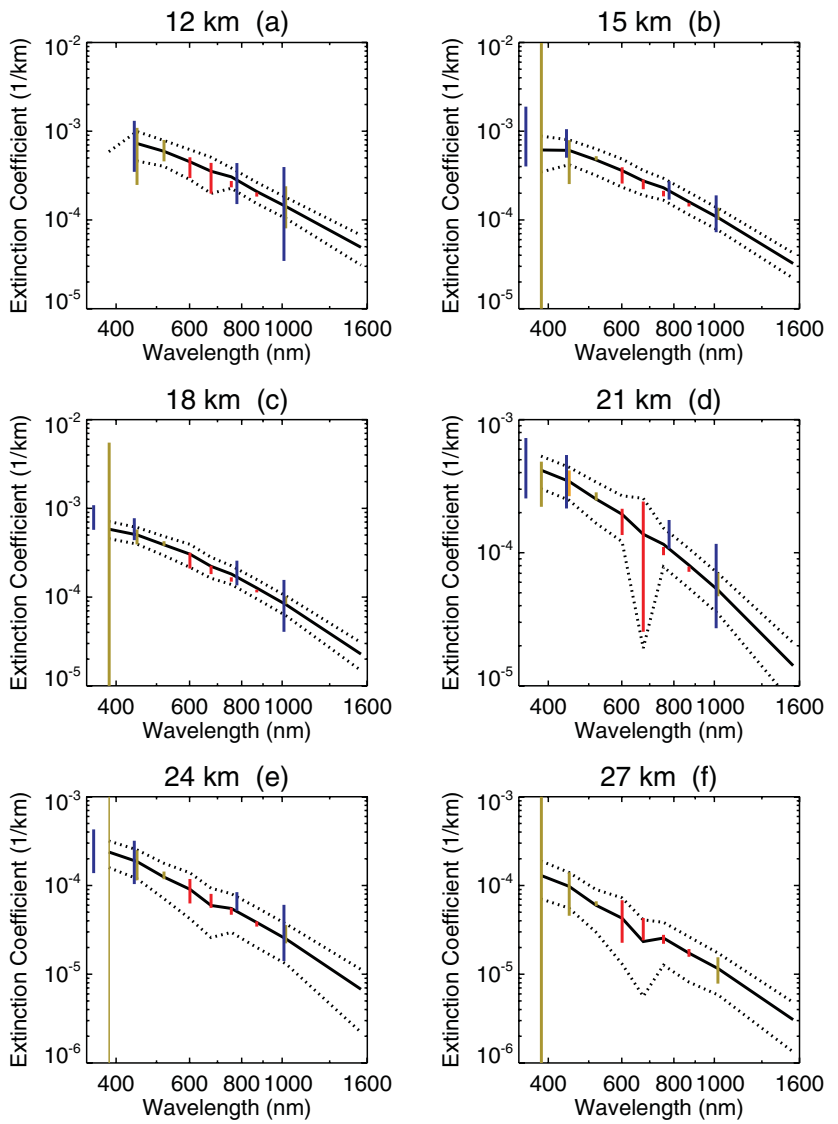

Fig. 5. Mean aerosol extinction coefficient spectra from SAGE III as solid line with $1-\sigma$ standard deviation shown as a dotted line with matched SAGE II (green), POAM III (blue), and values interpolated from SAGE III values at 449, 520, and $1020 \mathrm{~nm}$ using an Angstrom model (red) as vertical lines spanning $\pm 1-\sigma$. Data is shown at 12 (a), 15 (b), 18 (c), 21 (d), 24 (e), and $27 \mathrm{~km}$ (f).

means the differences between SAGE III and POAM III at this wavelength are even larger than the observed values particularly above $20 \mathrm{~km}$ where the aerosol spectrum is a steeper function of wavelength.

\subsection{Internal comparisons}

These results of matched pair comparisons are summarized in Fig. 5 which shows the mean aerosol extinction coefficient spectra with one standard deviation of the distribution for SAGE III at 6 altitudes from 12 to $27 \mathrm{~km}$ along with the matched data from POAM III and SAGE II. In general, we see that the extinction coefficient spectra are well organized with the exception of the SAGE III $676 \mathrm{~nm}$ aerosol extinction coefficient channel which shows increased noise and appears to be low relative to the other channels particularly at and above $21 \mathrm{~km}$ (Fig. 5d, e, and f). To test the quality of channels without a SAGE II equivalent $(601,676$, 755 , and $869 \mathrm{~nm}$ ), we interpolate aerosol extinction coefficient from SAGE III measurements at 449, 520, and $1021 \mathrm{~nm}$
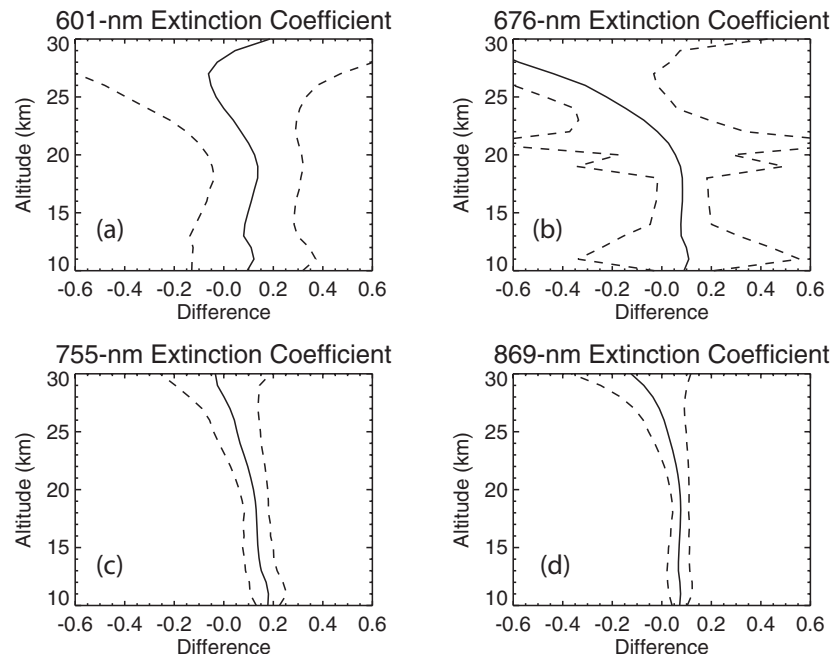

Fig. 6. Profile of the mean difference between comparisons of SAGE III version 4 aerosol extinction coefficient at $601 \mathrm{~nm}$ (a), 676 (b), 755 (c), and $869 \mathrm{~nm}$ (d) with values interpolated from SAGE III values at 449, 520, and $1020 \mathrm{~nm}$ using an Angstrom model as solid lines. The dashed lines show the range defined by 1 standard deviation $( \pm 1-\sigma)$.

using a simple Angstrom relationship such that extinction at any wavelength, $k(\lambda)$, is given by $k\left(\lambda_{1}\right)\left(\lambda / \lambda_{1}\right)^{\alpha}$ where the " 1 " subscript indicates a standard wavelength (in this case, $1021 \mathrm{~nm})$ and $\alpha$ is the computed power. It is important to note that, while interpolation schemes like the Angstrom relationship are reasonable approximations to observed aerosol spectra, the unseen details of the aerosol size distribution may create some significant departures. In fact, these can be seen in Fig. 5 where the spectra as a whole show appreciable curvature (particularly at lower altitudes) in a plotting space in which the Angstrom approximation would be straight. With only three channels to perform the interpolation, there is insufficient information to use a more complex form and some model-induced bias is inevitable. The curvature also makes it inadvisable to extrapolate to $1545 \mathrm{~nm}$ and a different evaluation is used below. Figure 6 shows the results of the interpolation. At $601 \mathrm{~nm}$ (Fig. 6a), we see a reasonable mean behavior with a consistent positive bias of approximately $10 \%$ but a large standard deviation of 20 to $30 \%$. This is not too surprising considering the large ozone signal at this wavelength and consistent with the POAM III comparisons shown above. This evaluation also shows that the $676 \mathrm{~nm}$ channel shows a significant bias above $20 \mathrm{~km}$ that rapidly increases with altitude such that bias exceeds $20 \%$ above $24 \mathrm{~km}$. The standard deviation is also large and exceeds $30 \%$ over most of the depth of the profile. This was expected to be a good aerosol channel and large noise and bias were unexpected. The other two channels show much greater promise. At $869 \mathrm{~nm}$, we find a mean bias of less than $10 \%$ (data greater than estimate) over most of the profile range 

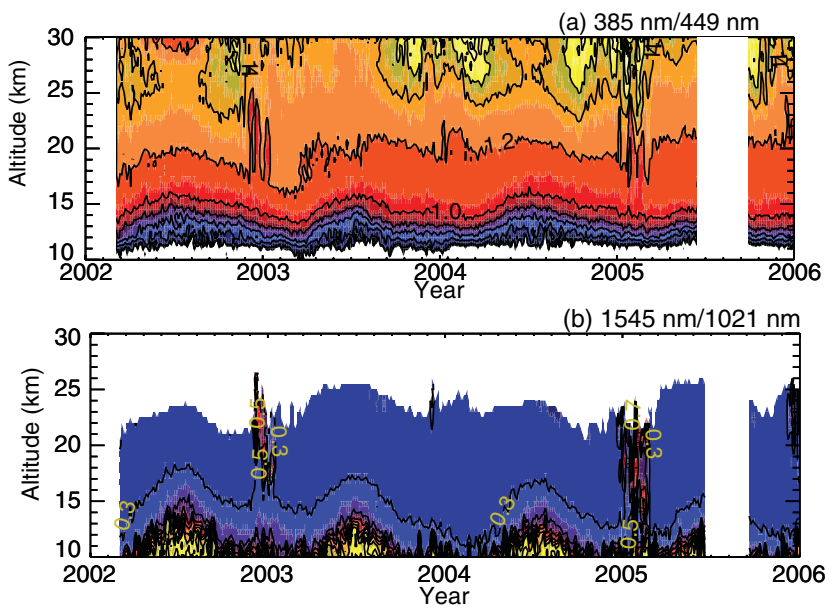

Fig. 7. SAGE III aerosol extinction coefficient ratio for 385-to$449 \mathrm{~nm}$ (a), and 1545-to-1021 nm (b) from February 2002 to December 2005 in bins of 0.02 years by $0.5 \mathrm{~km}$ requiring at least 5 data points per bin. Isopleths of extinction ratio are given every 0.2 ; color contours are given every 0.1 . The smallest values of extinction ratio are shown as dark blue and the largest values as yellow.
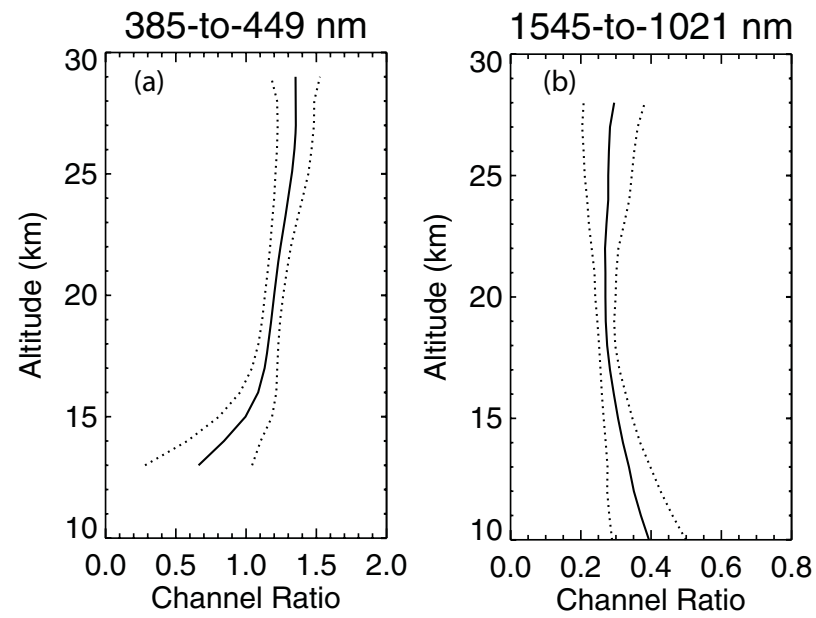

Fig. 8. Profiles of the average extinction coefficient ratios at 385-to$449 \mathrm{~nm}$ (a) and 1545-to-1021 nm (b) for all SAGE III events. The mean is shown as a solid line and the range defined by $\pm 1 \sigma$ are shown as dotted lines.

and a standard deviation of only $\sim 5 \%$. The sign of the bias is consistent with a linear interpolation over a curved spectra, thus we believe this channel to be consistent with the interpolating channels and possibly the strongest of the new channels. At the $755 \mathrm{~nm}$, the standard deviation is somewhat larger $(\sim 10 \%)$ as is the apparent interpolation bias though in this case it varies with altitude from $\sim 15 \%$ near $10 \mathrm{~km}$ and decreases to near zero at $30 \mathrm{~km}$. Since this wavelength is the mid way between the interpolation channels, the bias associated with the model would be at its largest and, as a result, we believe this channel to also be eminently usable.
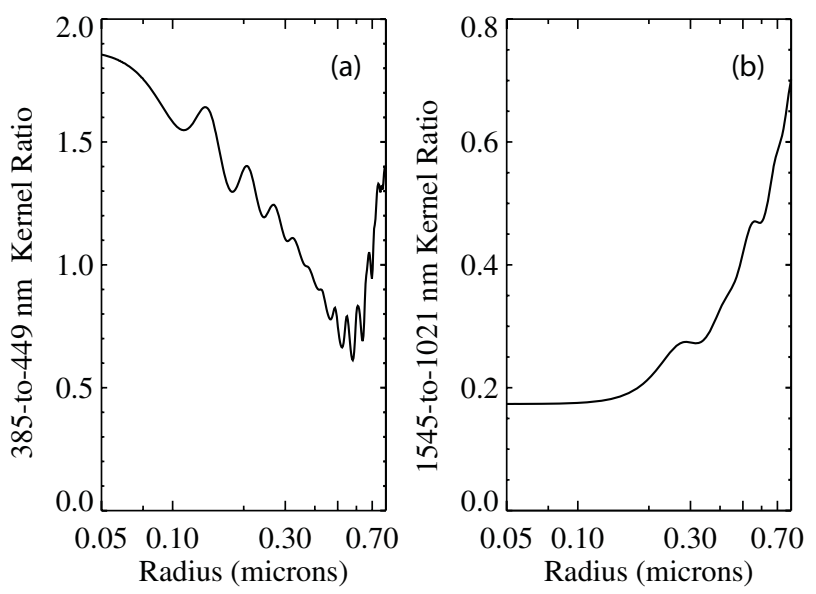

Fig. 9. The ratio of Mie extinction coefficient kernels at 385-to$449 \mathrm{~nm}$ (a) and 1545 -to- $1021 \mathrm{~nm}$ (b) for $25 \% \mathrm{H}_{2} \mathrm{SO}_{4} / 75 \% \mathrm{H}_{2} \mathrm{O}$ aerosol at stratospheric temperatures.

The final set of comparisons concern channels that are potentially the most interesting as they lie at the extremes of the SAGE III extinction coefficient wavelength range: 385 and $1545 \mathrm{~nm}$. We have previously shown some rather unsatisfactory comparisons of the $385 \mathrm{~nm}$ channel with SAGE II and POAM III. For at least SAGE II, we feel that deficiencies in the SAGE II product are likely to play a major role in the poor nature of these comparisons. Qualitatively, we see that the 385-nm channel as shown in Fig. 1a seems to behave in a manner consistent with other channels (e.g., Fig. 1b-e). To investigate the quality of the $385-\mathrm{nm}$ channel, we compared it to the extinction coefficient measurements at $449 \mathrm{~nm}$ which comparisons indicate is a high quality channel. Figure $7 \mathrm{a}$ shows the time history of the 385 -to- $449 \mathrm{~nm}$ aerosol extinction ratio for SAGE III Northern Hemisphere measurements and the mean profile is shown in Fig. 8a. Figure 9a shows the ratio of the Mie extinction kernels as a function of radius for 385 and $449 \mathrm{~nm}\left(\mathrm{H}_{2} \mathrm{O} / \mathrm{H}_{2} \mathrm{SO}_{4}\right.$ aerosol at stratospheric temperatures). The Mie calculations show that the observed extinction ratio below $15 \mathrm{~km}$, where it can be as small as 0.2 , is physically implausible and we conclude that the $385 \mathrm{~nm}$ channel is not useable at these altitudes. On the other hand, above $16 \mathrm{~km}$ the mean ratio is between 1.2 and 1.4 with a standard deviation of 4 to $15 \%$. While we are not attempting to infer any detailed information about the underlying size distribution, the observed ratio is consistent with extinction at these wavelengths being dominated by particles in the 0.15 to 0.30 micron range. Overall, while the range of the kernel ratio is 0.7 to 1.8 , it is difficult to imagine an extinction ratio for a realistic size distribution outside the range of 1.0 and 1.5. As a result, we conclude that it seems likely that bias in the $385-\mathrm{nm}$ channel relative to $449 \mathrm{~nm}$ extinction is no larger than $20 \%$ and probably less than $10 \%$ for altitudes above $16 \mathrm{~km}$ with a precision of $<10 \%$. 
For the 1545-nm channel, we compared it to the extinction coefficient measurements at $1021 \mathrm{~nm}$ which comparisons indicate is a reliable aerosol measurement. Figure $7 \mathrm{~b}$ shows the time history of the 1545 -to- $1021 \mathrm{~nm}$ aerosol extinction coefficient ratio for SAGE III Northern Hemisphere measurements and the mean profile is shown in Fig. 8b. Figure $9 \mathrm{~b}$ shows the ratio of the Mie extinction kernels as a function of radius for 1545 and $1021 \mathrm{~nm}\left(\mathrm{H}_{2} \mathrm{O} / \mathrm{H}_{2} \mathrm{SO}_{4}\right.$ aerosol at stratospheric temperatures). In this case, the stratospheric ratio is nearly constant between 0.27 and 0.33 and the ratio increasing to nearly 0.4 at $10 \mathrm{~km}$. The standard deviation is a minimum of $8 \%$ at $18 \mathrm{~km}$ and is $\sim 25 \%$ at 10 and $30 \mathrm{~km}$. The ratio values suggest extinction at these wavelengths is dominated by particles in the 0.2 to $0.5 \mu \mathrm{m}$ range. Given the possible range of ratio values, we believe that the accuracy of this channel is no worse than $20 \%$ and probably better than $10 \%$ above $15 \mathrm{~km}$. Due to the shape of the aerosol extinction kernels, we do not necessarily expect the particle ranges for the $1545 / 1021 \mathrm{~nm}$ ratio to match those found for the $384 / 449 \mathrm{~nm}$ ratio. Overall, the behavior of the $1545-\mathrm{nm}$ aerosol extinction coefficient data seems reasonable except perhaps below $15 \mathrm{~km}$ where the ratio seems a little large though we cannot clearly exclude this data. It is possible that extinction at $1545 \mathrm{~nm}$ could be overestimated by underestimating water vapor and/or carbon dioxide absorption corrections at this wavelength which are modest but significant below $15 \mathrm{~km}$.

\subsection{Recommendations on the use of SAGE III aerosol extinction coefficient data}

SAGE III provides a high quality aerosol data set with a wavelength span that can be useful in a number of applications. Only about half of the SAGE III channels have a direct comparison with measurements by other channels and we have employed some empirical techniques to evaluate some channels. While this is not fully satisfying, this evaluation provides the best estimate of the quality of the SAGE III aerosol extinction coefficient ensemble. As a result, we believe that the channels at 449, 520, 755, 869, and $1021 \mathrm{~nm}$ to be solid channels with accuracies and precisions on the order of $10 \%$ in the primary aerosol range of 15 to $25 \mathrm{~km}$. We also believe this to be true of the aerosol channel at $1545 \mathrm{~nm}$ though we cannot exclude some positive bias below $15 \mathrm{~km}$. Similarly, it is apparent that the $385 \mathrm{~nm}$ channel is significantly biased below $15 \mathrm{~km}$ and can only recommend its use above $16 \mathrm{~km}$ where the accuracy is on par with other aerosol channels (10-20\% accuracy, $10 \%$ precision). Nominally, we find the $601 \mathrm{~nm}$ channel is of a similar accuracy as other channels $(\sim 10 \%)$ but is much noisier $(\sim 20 \%)$ than these other channels and we suggest caution in this channel's use. We believe that the $676 \mathrm{~nm}$ channel is clearly defective particularly above $20 \mathrm{~km}$ (accuracy as poor as $50 \%$ ) and the precision is also low $(\sim 30 \%)$. While the evaluation may indicate that this channel could be used below $20 \mathrm{~km}$, we suggest excluding this channel under most circumstances. As with any data set, since bias is mostly independent from one channel to another, users should exercise caution in any mathematical retrieval application (e.g., size distribution/surface area density) as even the modest potential bias in these measurements may result in unpredictable results.

\section{Water vapor}

The water vapor retrieval employs 28 individual pixels (or channels) on the spectrometer's CCD detector that span the wavelength range from 931 to $960 \mathrm{~nm}$ or nearly spanning the $\rho \sigma \tau$ water vapor absorption band. The channels are spaced $\sim 1.0 \mathrm{~nm}$ apart and the FWHM for the individual channels is $1.2 \mathrm{~nm}$ and the measurement precision is close to $0.1 \%$. In the preflight algorithm, we removed the contribution of ozone absorption and molecular and aerosol scattering using the primary ozone measurement, molecular scattering calculated from NCEP temperature data (Bloom et al., 2005), and the interpolation of nearby aerosol channels to the water vapor measurement wavelength locations. The remaining optical depth is assumed to be due to water vapor absorption and water vapor mixing ratio is inferred using a global fit algorithm (SAGE III ATDB, 2002).

Specifically, we employed the well known Marquardt method (Marquardt, 1963) to perform non-linear least squares that simultaneously fit absorption measurements from the 28 spectral channels at all altitudes. The Marquardt method minimizes a merit function using an iterative procedure that alternates between the inverse-Hessian method and the steepest descent method as appropriate. In this case, the merit function, $\mu$, is defined as

$\mu=\sum_{I} \sum_{J} \frac{\left(A_{i j}-A_{i j}^{g}(\chi)\right)^{2}}{\sigma_{i j}^{2}}$

where $\sigma_{i j}$ are the measured uncertainties, $A_{i j}$ are the measured absorption values (corrected for Rayleigh, aerosol, and ozone) for slant path $j$ and water vapor channel $i ; A_{i j}^{g}$ are the computed absorption values for slant path $j$, channel $i$, and the current guess for the water vapor mixing ratio profile $\chi$. To compute absorption, we used the emissivitycurve-of-growth approximation (EGA) as the forward model for water vapor absorption (Gordley and Russell, 1980). This method is extremely computationally efficient and was found to yield virtually identical results as a more computationally demanding line-by-line approach. This method requires derivatives of absorption as a function of temperature, pressure and line-of-sight molecular number density which are also precalculated and stored for each channel as a part of a water vapor absorption data base (Benner et al., 1995). The water vapor absorption band is relatively weak in the stratosphere and the peak absorption for the band including the interfering species is only about $1 \%$ for a limb observation with 
a tangent altitude near the tropopause. We use the water vapor line parameters provided by Brown et al. (2002). Prior to launch, the expected SAGE III instrument measurement capability suggested that the water vapor mixing ratio accuracy could be as good as $3 \%$ to $4 \%$. More conservatively, with the consideration of the uncertainty in the temperature retrieval, altitude registration, and in the removal of contribution due to interfering species, including molecular scattering, aerosols, and ozone, we expected a water vapor precision between $5 \%$ to $15 \%$ in the altitude range of 5 and $40 \mathrm{~km}$. The nominal target precision and accuracy for water vapor were 15 and $10 \%$ from 5 to $50 \mathrm{~km}$ (SAGE III ATDB, 2002).

As mentioned in the introduction, we found that both version 2 and 3 water vapor products were of considerably lower quality than expectation and were therefore not released to the public. Below we discuss the changes in the Version 4 processing, particularly decreasing noise in the LOS transmission and improved ozone cross sections, which allowed the production of a water vapor data product that is close to preflight expectations and allow its release in this version. In addition, we show comparisons with other space-based water vapor measurements including those by SAGE II, POAM III, the Halogen Occultation Experiment (HALOE), and the Microwave Limb Sounder (MLS/Aura). Validation for their water vapor data products can be found in Taha et al. (2004), Lumpe et al. (2006), Harries et al. (1996) and Lambert et al. (2007), respectively.

\subsection{Issues related to the retrieval of water vapor}

The version 3 water vapor data product was judged to be defective due to these features: a high level of noise in individual profiles, and a clear negative bias in the lower stratosphere. We originally believed that the primary culprit was a thick plate etalon in all solar occultation spectra that was caused by the use of an unwedged neutral density filter (usually referred to as the solar attenuator) in the optical path. This turned out to play a small role and we found that improvements to the Level 1 transmission algorithm and updating the ozone cross section data were the keys to an improved product. There is also an intermittent ephemeris data issue in 2002 where some data should be avoided.

\subsubsection{The thick plate etalon}

The solar attenuator plate allows the use of the instrument in both solar and lunar occultation modes as well as limb scattering mode. It is required because, depending upon phase, the Moon is between one million and ten million times less luminous than the Sun. The solar attenuator is a neutral density filter with an attenuation of $\sim 4000$. By removing it from the optical path during lunar events along with changes to integration time (from 64 to $256 \mathrm{~ms}$ ) and the number of rows in the detector used between modes ( 3 in solar mode compared to 8 in lunar mode) compensates for this large change in il-

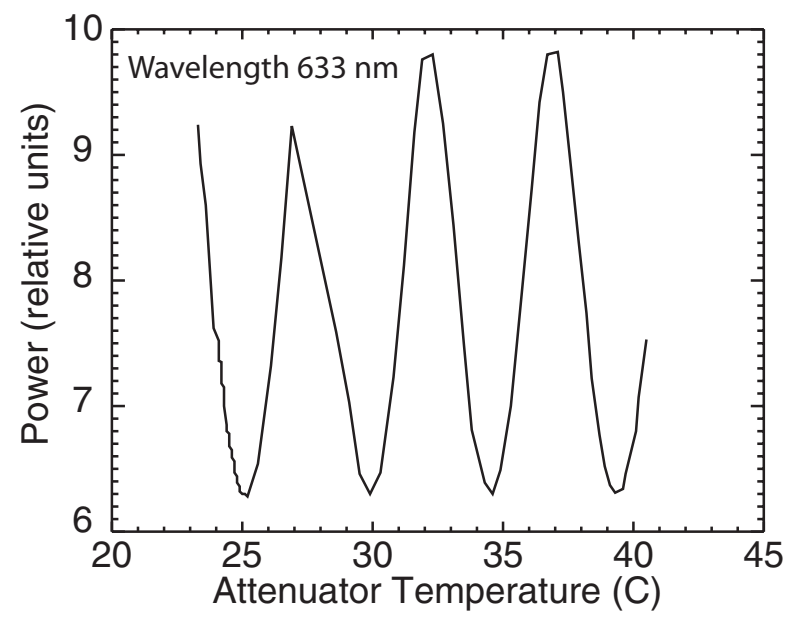

Fig. 10. The power throughput of a 633-nm HeNe laser through a sample of the SAGE III solar attenuator as a function of temperature.

lumination. Nominally, the presence of the solar attenuator during solar events would not be an issue. Unfortunately, the attenuator which specified to be wedged at less than 1 arcmin is actually plane parallel. This creates a thick plate etalon for all measurement wavelengths with a repetition of 8 to 10 cycles per pixel and amplitude of about $10 \%$ both of which are a function of wavelength. Figure 10 shows an example of the throughput of a HeNe laser $(633 \mathrm{~nm})$ through a section of attenuator from the same manufacturing batch. It shows the change in phase of the etalon as a function of temperature due to changes in the attenuator's refractive index. From the SAGE perspective, the phase of the etalon is a quasi-function of time or altitude due to the warming of the attenuator during an event as it is exposed to the Sun. Based on laboratory experiments, we believe that the etalon completes about 3 cycles per event for a nominal event time of approximately $3 \mathrm{~min}$.

The presence of the etalon manifests itself as a time dependent change to the spectral response of the individual pixels and impacts both the calculation of the exoatmospheric Sun brightness $\left(I_{0}\right)$ and the LOS transmission. It is particularly relevant to the water vapor retrieval due to the small water vapor absorption in this band. Since the $\mathrm{I}_{0}$ calculations are made for tangent heights around $150 \mathrm{~km}$, we compensate for the change in $I_{0}$ due to changes in the phase of the etalon by renormalizing the spectra at all altitudes using the mean Level 1 transmission in the water vapor channels between 90 and $100 \mathrm{~km}$ where transmission should be 1 . Figure 11 shows the uncorrected transmission between 90 and $100 \mathrm{~km}$ and the mean value. This correction has a small but positive impact on the quality of the water vapor data product in Version 4. The impact on transmission is more subtle and effectively manifests itself as 'noise' in the transmission profiles when we average individual measurements in an altitude 


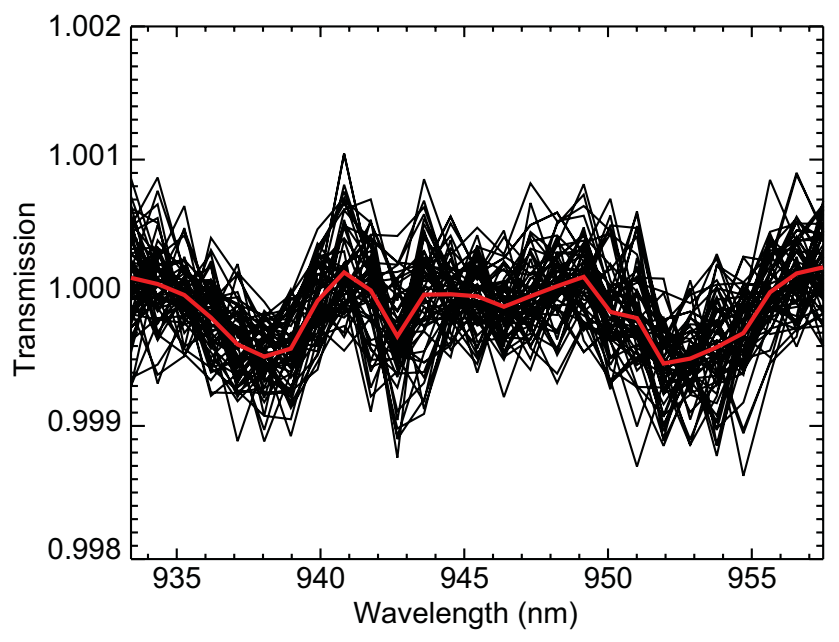

Fig. 11. SAGE III transmission between 90 and $100 \mathrm{~km}$ for one channel in the water vapor absorption band (black) along with the mean transmission in this layer (red).

bin from different times and, concomitantly, different phases of the shifting etalon. While we made several attempts to account for these changes, we did not find any practical solution that resulted in an improvement to the final product and it remains difficult to quantify the level of noise that this creates in the level 1 transmission data and the end product.

\subsubsection{Improved transmission}

Given the intractability of the noise created by the etalon, an aggressive approach to improving transmission was critical to the improvement of the SAGE III water vapor product. A key factor for improving transmission quality was the incorporation of tools for improved altitude registration and scan co-registration developed for SAGE II. These are primarily focused on improving detection of the Sun's edges in individual scans and nudging scans in altitude (typically on the order of 10's of meters) to reduce transmission noise in the composite transmission profile. We have also incorporated a mechanism that accounts for changes in $\mathrm{I}_{0}$ that result from the apparent rotation of the Sun in the reference frame of the spacecraft (Burton et al., 2010). Finally, to further reduce measurement noise, we apply a 1-2-1 vertical smoothing to each of the 28 channels in the water vapor retrieval which reduces noise by roughly a factor of $1 / \sqrt{ } 2$ and increases vertical resolution from $\sim 0.7 \mathrm{~km}$ to $\sim 1.5 \mathrm{~km}$. Figure 12 shows the change in the relative error in transmission (averaged for the 28 water vapor channels) between Version 3 and Version 4. We find that the algorithm changes between versions have reduced the measurement uncertainty by about a factor of 2 .

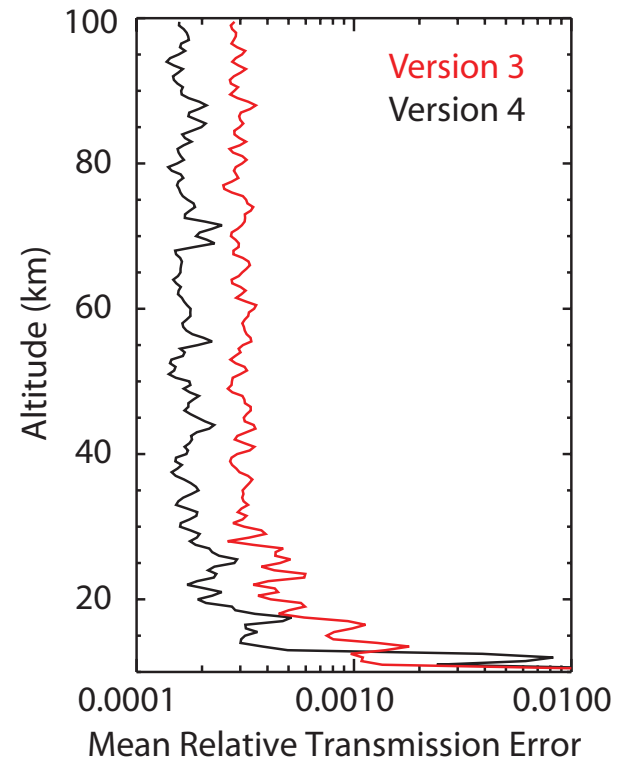

Fig. 12. Mean transmission error for the 28 channels in SAGE III water vapor band as a function of altitude for Version 4 (black) and Version 3 (red).

\subsubsection{Ozone spectroscopy}

The most significant change from Version 3 to Version 4 was a change from the Shettle and Anderson (1994) ozone cross section compilation to the Bogumil et al. (2003) measurements made in support of SCIAMACHY. For this application, the most relevant difference between these two data sets are found in Wulf band structures which encompass the wavelengths used for the water vapor retrieval. In the new data set the amplitude of the Wulf band absorption ripple is much more pronounced than those in the Shettle/Anderson compilation. As mentioned in the aerosol section, this update removed a clear ozone artifact in the $755 \mathrm{~nm}$ aerosol extinction coefficient data (Thomason and Taha, 2003). In addition, Pitts et al. (2006) found that in-atmosphere measurements by the Gas and Aerosol Measurement (GAMS) which spanned the Chappuis and the Wulf band tended to favor the SCIAMACHY set. While values are on average not greatly different between the two data sets, we found that the difference in the cross sections drove the retrieved water vapor toward smaller values particularly in the lower stratosphere and this was the primary source of the bias observed with other data sets in Version 3. The mean relative difference from Version 3 to Version 4 water vapor is shown in Fig. 13. In this comparison, we see a $20 \%$ increase in water vapor from 10 to about $40 \mathrm{~km}$ with a turn over to a decrease in water vapor mixing ratio above $40 \mathrm{~km}$. This change is mostly driven by changes in the ozone cross sections. We also see about a $20 \%$ to $30 \%$ variance below $40 \mathrm{~km}$. Much of this is driven by the transmission noise in Version 3 and is greatly reduced in Version 4 as demonstrated below. 


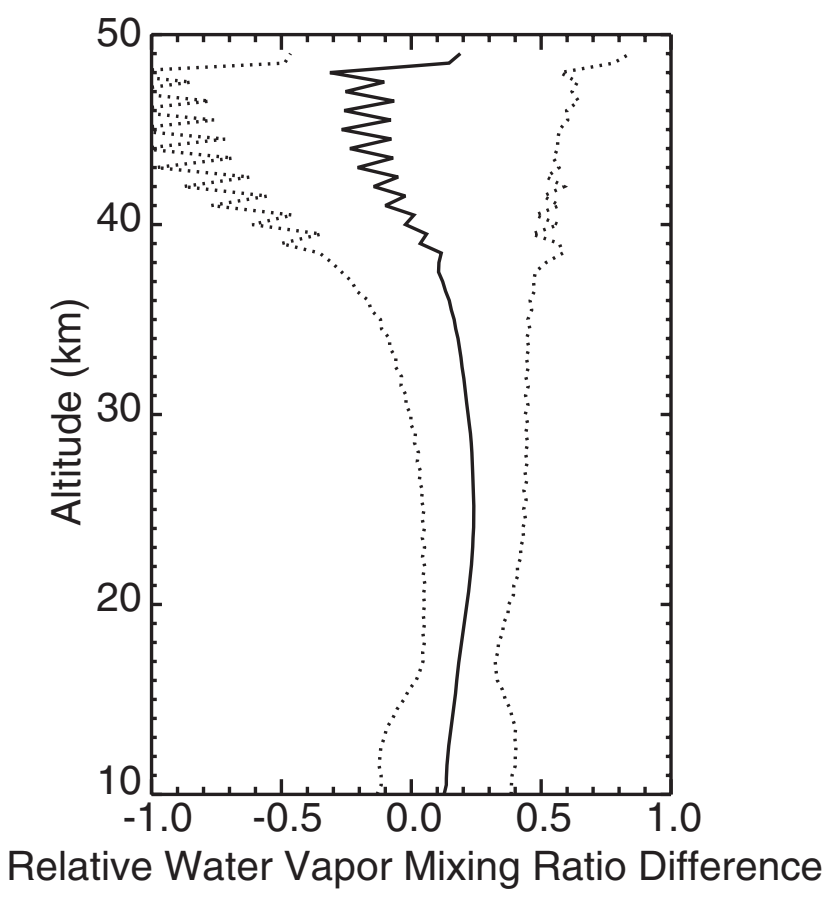

Fig. 13. The mean relative difference between SAGE III Version 4 water vapor mixing ratio profile with Version 3 . The dotted lines show the range defined by 1 standard deviation $( \pm 1-\sigma)$.

\subsubsection{Spacecraft ephemeris data}

Figure 14 shows a 1-week average of Northern Hemisphere SAGE III water vapor mixing ratio from the beginning of the mission to the end of 2005. The figure shows a strong annual cycle and evidence of a biennial cycle in the lower stratosphere where the dryer stratospheres correspond to years with few PSCs observed. Above $30 \mathrm{~km}$ there is evidence for water descent during boreal summer. In addition, there is a hint of the descent of dry air immediately after the end of the downward transport period. There are three periods of anomalies in the second half of 2002 where the water vapor mixing ratio are clearly smaller than adjacent periods. Examining the anomaly in detail, we find that the offset occurs exactly in 7-day periods beginning at 00:00 UTC Sunday and ending at 00:00 UTC the following Sunday for the weeks beginning on Julian days 258,300 , and 321 . This matches our spacecraft ephemeris update periods and we believe that deficient ephemeris data for these periods is the most likely source of the error. The impact seems confined to the water vapor product due to its weak signal strength and we currently recommend avoiding this period for this product only.

\subsection{Comparisons with other space-borne sensors}

To match events with SAGE II, POAM III, HALOE (v19), and MLS (v2.2) we have used the same criteria as used for the aerosol comparisons following Thomason et al. (2007) and Randall et al. (2001). This defined a coincidence at a

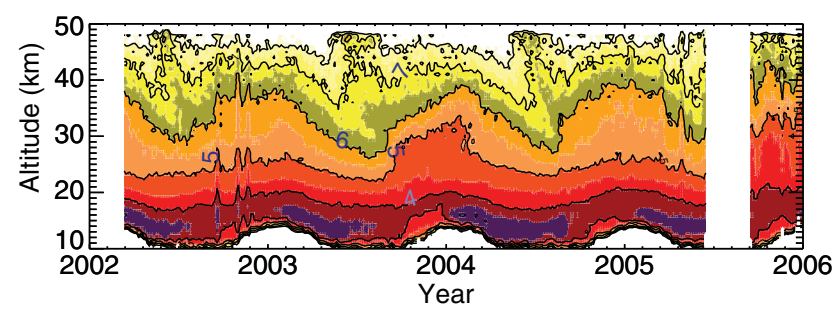

Fig. 14. SAGE III water vapor mixing ratio from February 2002 to December 2005 in bins of 1 week by $0.5 \mathrm{~km}$ requiring at least 5 data points per bin. Isopleths of mixing ratio are given every $1.0 \mathrm{ppm}$; color contours are given every $0.5 \mathrm{ppm}$. The lowest water vapor mixing ratios are shown as purple and the largest values are shown as yellow.

given altitude for events within \pm 1 day, $\pm 24^{\circ}$ longitude, and $\pm 5 \%$ of the potential vorticity (PV) range observed in the SAGE III Northern Hemisphere data and $\pm 4^{\circ}$ difference in latitude. We also eliminated all coincidences where relative errors are greater than $75 \%$. Unlike for aerosols, we do not remove suspected cloud events including PSCs and, since PV data is not available for the HALOE and MLS comparisons, that factor is not included in the identification of coincident events for those instruments. In addition, MLS-SAGE III coincidences can have as many as 20 MLS events that pass the coincidence criteria for a single SAGE III event. For these comparisons, we use only the closest MLS event. POAM III and SAGE II have the same number of coincident events as they have for aerosol comparisons. HALOE has about 200 coincident events and MLS about 8400 or about half of all SAGE III events during the 1.5 years of overlap between the missions.

The comparisons with all four instruments are shown in Fig. 15. In Fig. 15a, comparisons with SAGE II show a virtually constant offset of 8 to $15 \%$ from 10 to $40 \mathrm{~km}$ with a slight negative tilt above that altitude. The standard deviation is less than $15 \%$ from 15 to $31 \mathrm{~km}$ and slowly increases above that altitude to about $30 \%$ at $45 \mathrm{~km}$. Some increase in standard deviation between 15 and $10 \mathrm{~km}$ is expected since the vertical gradient in water vapor can be large in this altitude range and spatial variability at and below the tropopause can be quite large (compared to the stratosphere). For SAGE II comparisons, the standard deviation increases from $\sim 10 \%$ at $15 \mathrm{~km}$ to $\sim 40 \%$ at $10 \mathrm{~km}$. The POAM III comparisons are shown in Fig. 15b. In this case, the mean differences are between $-10 \%$ and $1 \%$ from 10 to $40 \mathrm{~km}$ and tilts toward more positive differences above that altitude. The standard deviation in the comparison is between 10 and $15 \%$ from 15 to $45 \mathrm{~km}$. In this case, the standard deviation between 10 and $15 \mathrm{~km}$ is much larger than in the SAGE II comparison and greater than $100 \%$ below $13 \mathrm{~km}$. This appears to be driven by POAM III measurement noise that is substantially damped for altitudes above $15 \mathrm{~km}$. Generally, these comparisons show a good agreement. 

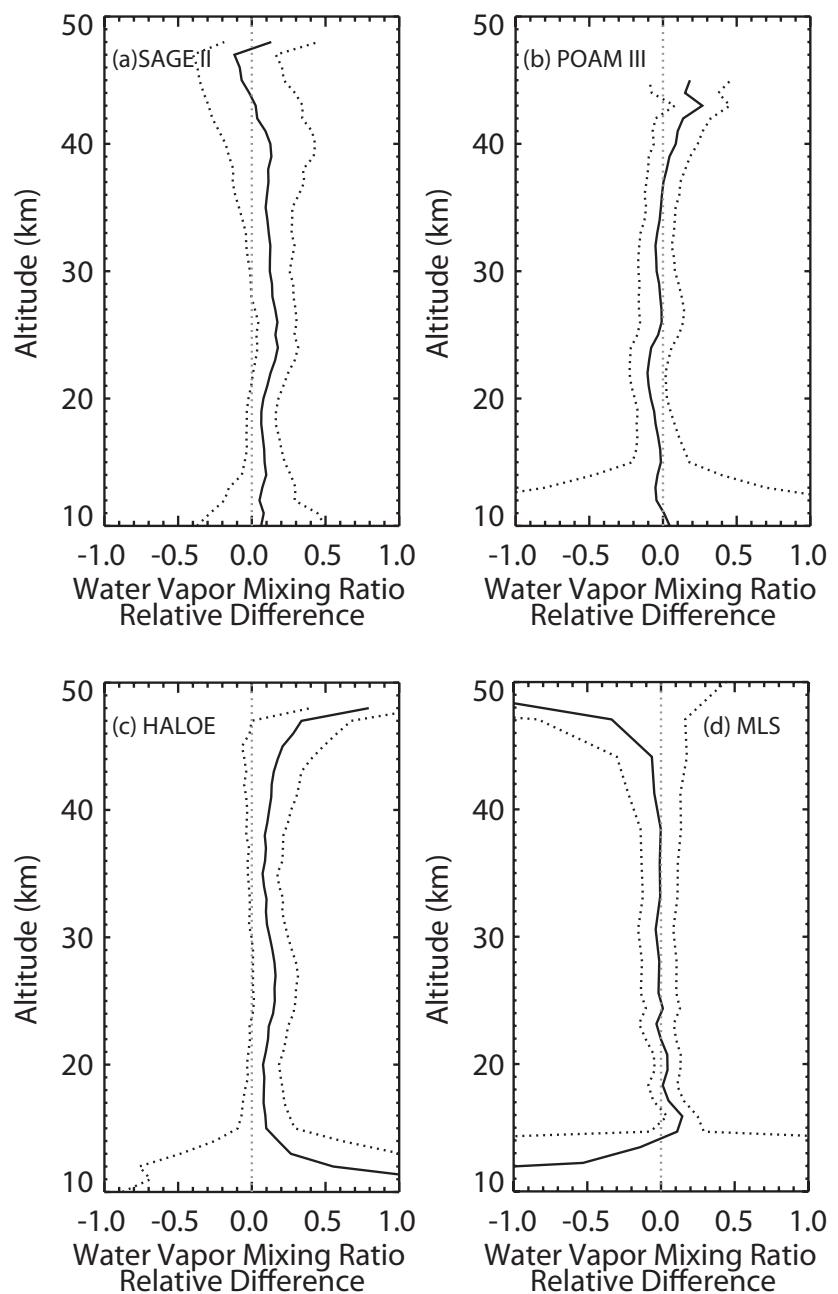

Fig. 15. Profile of the mean difference (other instrument/SAGE III) between SAGE III version 4 water vapor mixing ratio with SAGE II (a), POAM III (b), HALOE (c), and MLS (d). The dotted lines show the range defined by 1 standard deviation $( \pm 1-\sigma)$.

HALOE is a solar occultation instrument operating in the infrared (so no directly comparable aerosol measurements). Because of the vagaries of the orbits of the host platforms (Meteor 3M and UARS), HALOE has limited coincidences with SAGE III. MLS on the other hand is a microwave limb emission instrument that makes profile measurements continuously during an orbit unlike solar occultation instruments that only make measurements when crossing the terminator (i.e., twice an orbit). As a result, MLS has many coincident measurements with SAGE III particularly given the broad coincidence criteria. The SAGE III/HALOE comparisons show a mean difference of 10 to $15 \%$ from 15 to $45 \mathrm{~km}$. From 15 to $40 \mathrm{~km}$, the standard deviation is between 10 and $15 \%$ and slowly increases above this altitude. There are larger differences below $15 \mathrm{~km}$ in a region where it is known that HALOE v19 water vapor tends to be too large (SPARC, 2000). The comparison with MLS is particularly

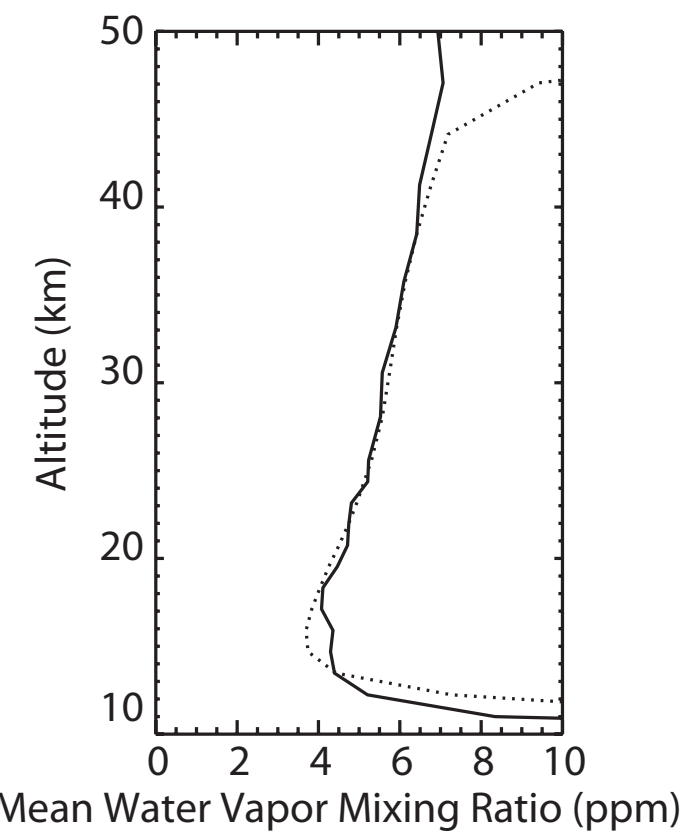

Fig. 16. Mean SAGE III (dotted) and MLS (solid) water vapor mixing ratio profiles for $\sim 8000$ coincident events from mid-2004 through 2005.

good. Note we have included the correction suggested by Lambert et al. (2007) that effectively removes a slight oscillation in the MLS water vapor data between 20 and $25 \mathrm{~km}$. The mean difference is less than $3 \%$ from 15 to $45 \mathrm{~km}$ with a standard deviation at a nearly constant $10 \%$. The differences are much larger above $45 \mathrm{~km}$ which is a region where we expect SAGE III water vapor data quality to decline. HALOE shows a similar (but smaller) difference with SAGE III above $45 \mathrm{~km}$ and it seems likely that both MLS and HALOE measurements in these altitudes are more robust than those by the SAGE instruments. As a result we conclude that SAGE III data above $45 \mathrm{~km}$ are not good quality measurements. Below $17 \mathrm{~km}$, the mean difference briefly dips to $15 \%$ at $16 \mathrm{~km}$ before becoming very large ( $>100 \%)$ below $12 \mathrm{~km}$. While this difference is difficult to explain due to spatial variability and spatial resolution, it seems likely that at least part of the difference is that MLS and SAGE III resolved the hygropause differently due to differences in their vertical resolutions. Nevertheless, the SAGE III and MLS comparisons show an outstanding level of agreement between 15 and $45 \mathrm{~km}$ suggesting that both data sets are very good in this altitude range.

\subsection{Recommendations for the use of SAGE III water va- por data}

The SAGE III Version 4 water vapor data product appears to be high quality and is recommended for science applications in the stratosphere below $45 \mathrm{~km}$. In this altitude range, the mean difference with all four corroborative data sets are 
no bigger than $15 \%$ and generally less than $10 \%$ with exceptional agreement with POAM III and MLS. Above $45 \mathrm{~km}$, it seems likely that SAGE III water vapor values are increasingly too large and should be used cautiously or avoided. The standard deviations in these profiles are between 10 and $15 \%$ from $15 \mathrm{~km}$ to $40 \mathrm{~km}$ for SAGE III comparisons with POAM III, MLS, and HALOE and between 10 and 25\% (increasing with height) for SAGE II. Based on these comparisons, we believe that SAGE III meets its preflight goal of $15 \%$ accuracy and $10 \%$ precision between 15 and $45 \mathrm{~km}$. In the troposphere, the comparisons are more difficult to interpret due to much greater spatial and temporal variation than in the stratosphere and the impact of differences in vertical resolution among the instruments in the comparison. That said, we are modestly optimistic that the SAGE III data is usable in the upper troposphere with caveats regarding the spatial resolution of the measurements and the restriction to "cloud-free" observations. Unlike SAGE II (Thomason et al., 2004; Taha et al., 2004), given the low aerosol loading in the stratosphere throughout the mission lifetime, we do not currently limit the SAGE III water vapor data utility in the stratosphere by aerosol loading. The data in 2002 is occasionally impacted by deficient ephemeris data for seven day periods starting with Julian days 258,300 , and 321 . We do not recommend using SAGE III water vapor data in these time periods.

\section{Conclusions}

We have examined the SAGE III aerosol extinction coefficient and water vapor data sets and shown them to be suitable for science applications subject to some minor caveats. For aerosol extinction coefficient, the channels at 449, 520, 755, 869 , and $1021 \mathrm{~nm}$ are reliable with accuracies and precisions on the order of $10 \%$ in the primary aerosol range of 15 to $25 \mathrm{~km}$ and viable from 10 to $30 \mathrm{~km}$. This is also true of the $1545-\mathrm{nm}$ channel though care should be used below $15 \mathrm{~km}$. We do not recommend the use of the 385-nm channel below $16 \mathrm{~km}$ nor do we recommend using at any altitude either the 601-nm channel due to high measurement noise ( $\sim 20 \%)$ or using the $676 \mathrm{~nm}$ channel because it is substantially biased in this version. The SAGE III water vapor product below $45 \mathrm{~km}$ shows a general agreement with SAGE II, MLS, HALOE, and POAM III. It is particularly good with MLS where the mean agreement is within $\sim 5 \%$ from 15 to $45 \mathrm{~km}$. The agreement with POAM III is within $10 \%$ between 10 and $40 \mathrm{~km}$. For both SAGE II and HALOE, the agreement is systematic but apparently biased by about $+10 \%$ from 10 to $45 \mathrm{~km}$ for SAGE II and about $+10 \%$ from 15 to $45 \mathrm{~km}$ for HALOE. This takes on added significance due to the correlation between SAGE II and HALOE water vapor measurements (Thomason et al., 2004). The standard deviations in these comparison profiles are between 10 and 25\% (increasing with height) from $15 \mathrm{~km}$ to $40 \mathrm{~km}$. SAGE III water vapor values above $45 \mathrm{~km}$ show a systematic high bias and we do not recommend them for science applications. Unlike SAGE II (Thomason et al., 2004; Taha et al., 2004), we do not see a requirement for an aerosol-based limitation for SAGE III water vapor data utility in the stratosphere. Finally, SAGE III water vapor data quality in 2002 for seven day periods starting with Julian days 258,300 , and 321 is reduced by deficient ephemeris data and should be avoided.

Acknowledgements. The solar attenuator test was performed by Ed Burcher, Joseph Goad, and Michael Cisewski of NASA Langley Research Center and archived as SAGE III Technical Memorandum TM 2003-243 and is available from the authors.

Edited by: W. Lahoz

\section{References}

Benner, D. C., Rinsland, C. P., Malathy Devi, V., Smith, M. A. H., and Atkins, D.: A multispectrum nonlinear least squares fitting technique, J. Quant. Spectrosc. Radiat. Transfer, 53, 705-721, 1995.

Bloom, S., da Silva, A., Dee, D., Bosilovich, M., Chern, J.-D., Pawson, S., Schubert, S., Sienkiewicz, M., Stajner, I., Tan, W.-W., and $\mathrm{Wu}$, M.-L.: Documentation and Validation of the Goddard Earth Observing System (GEOS) Data Assimilation System Version 4, Technical Report Series on Global Modeling and Data Assimilation, 104606, 26, 2005.

Bogumil, K., Orphal, J., Homann, T., Voigt, S., Spietz, P., Fleischmann, O. C., Vogel, A., Hartmann, M., Bovensmann, H., Frerick, J., and Burrows, J. P.: Measurements of molecular absorption spectra with the SCIAMACHY pre-flight model: instrument characterization and reference data for atmospheric remotesensing in the 230-2380 nm region, J. Photochem. Photobiol. A, 157-167, 2003.

Brown L. R., Toth, R. A., and Dulick, M.: Empirical line parameters of $\mathrm{H}_{2}^{16} \mathrm{O}$ near $0.94 \mu \mathrm{m}$ : positions, intensities and air-broadening coefficients, J. Mol. Spectrosc., 212, 57-82, 2002.

Burkholder, J. B. and Talukdar, R. K.: Temperature dependence of the ozone absorption spectrum over the wavelength range 410 to 760 nm, Geophys. Res. Lett., 21, 581-584, 1994.

Burton, S. P., Thomason, L. W., and Zawodny, J. M.: Technical Note: Time-dependent limb-darkening calibration for solar occultation instruments, Atmos. Chem. Phys., 10, 1-8, 2010, http://www.atmos-chem-phys.net/10/1/2010/.

Gordley, L. L. and Russell, J. M.: A fast and accurate radiance algorithm for applications to inversion of limb measurements, in Remote Sensing of Atmospheres and Oceans, edited by A. Deepak, Academic Press, San Diego, CA, USA, 591-607, 1980.

Harries, J. E., Russell III, J. M., Tuck, A. F., Gordley, L. L., Purcell, P., Stone, K., Bevilacqua, R. M., Gunson, M., Nedoluha, G., and Traub, W. A.: Validation of measurements of water vapor from the Halogen Occultation Experiment (HALOE), J. Geophys. Res., 101(D6), 10205-10216, 1996.

Kent, G. S., Trepte, C. R., Farrukh, U. O., and McCormick, M. P.: Variation in the stratospheric aerosol associated with the north cyclonic polar vortex as measured by the SAM II satellite sensor, J. Atmos. Sci., 42, 1536-1551, 1985. 
Lambert, A., Reade, W. G., Livesey, N. J., et al.: Validation of the Aura Microwave Limb Sounder middle atmosphere water vapor and nitrous oxide measurements, J. Geophys. Res., 112, D24S36, doi:10.1029/2007JD008724, 2007.

Lumpe, J. D., Bevilacqua, R. M., Hoppel, K. W., and Randall, C. E.: POAM III retrieval algorithm and error analysis, J. Geophys. Res., 107(D21), 4575, doi:10.1029/2002JD002137, 2002.

Lumpe, J., Bevilacqua, R., Randall, C., Nedoluha, G., Hoppel, K., Russell, J., V. L. Harvey, C. Schiller, B. Sen, G. Taha, G. Toon, H. Vomel, Validation of Polar Ozone and Aerosol Measurement (POAM) III version 4 stratospheric water vapor, J. Geophys. Res., 111, D11301, doi:10.1029/2005JD006763, 2006.

Manney, G. L., Michelsen, H. A., Bevilacqua, R. M., Gunson, M. R., Irion, F. W., Livesey, N. J., Oberheide, J., Riese, M., Russell III, J. M., Toon, G. C., and Zawodny, J. M.: Comparison of satellite ozone observations in coincident air masses in early November 1994, J. Geophys. Res., 106, 9923-9943, 2001.

Marquardt, D.: An Algorithm for Least-Squares Estimation of Nonlinear Parameters, J. Appl. Math., 11, 431-441, 1963.

Pitts, M. C., L. W. Thomason, J. M. Zawodny, B. N. Wenny, J. M. Livingston, P. B. Russell, Yee, J.-H., Swartz, W. H., and Shetter, R. E., Ozone observations by the Gas and Aerosol Measurement Sensor during SOLVE II Atmos. Chem. Phys., 6, 2695-2709, 2006,

http://www.atmos-chem-phys.net/6/2695/2006/.

Poole, L. R., Trepte, C. R., Harvey, V. L., Toon, G. C., and Van Valkenburg, R. L.: SAGE III observations of Arctic polar stratospheric clouds - December 2002, Geophys. Res. Lett., 30(23), 2216, doi:10.1029/2003GL018496, 2003.

Randall, C.E., Bevilacqua, R. M., Lumpe, J. D., and Hoppel, K. W.: Validation of POAM III aerosols: Comparison to SAGE II and HALOE, J. Geophys. Res., 106(D21), 27525-27536, 2001.

Rault, D. F.: Ozone profile retrieval from Stratospheric Aerosol and Gas Experiment (SAGE III) limb scatter measurements, J. Geophys. Res., 110, D09309, doi:10.1029/2004JD004970, 2005.

Rault, D. F. and Taha, G.: Validation of ozone profiles retrieved from Stratospheric Aerosol and Gas Experiment III limb scatter measurements, J. Geophys. Res., 112, D13309, doi:10.1029/2006JD007679, 2007.

SAGE III ATDB: SAGE III Algorithm Theoretical Basis Document: Solar and Lunar Algorithm, Earth Observing System Project science Office web site online available at: http://eospso. gsfc.nasa.gov, 2002.
Shettle, E. P. and Anderson, S. M.: New Visible and Near IR Ozone Cross Sections for MODTRAN, presented at the 17th Annual Review Conference on Atmospheric Transmission Models, Phillips Laboratory, Bedford, MA, USA, 7-8 June 1994.

SPARC 2000: SPARC Assessment of Upper Tropospheric and Stratospheric Water Vapour, SPARC Report No.2, WCRP - 113, WMO/TD - No. 1043, December 2000, edited by: Kley, D., Russell III, J. M., and Phillips, C.

SPARC. 2006, Assessment of Stratospheric Aerosol Properties (ASAP), SPARC Report No. 4, WCRP-124, WMO/TD-No. 1295, Feb. 2006, L. Thomason and Th. Peter, Eds.

Taha, G., Thomason, L. W., and Burton, S. P.: Comparison of SAGE II Version 6.2 water vapor with balloon-borne and space-based instruments, J. Geophys. Res., 109, D18313, doi:10.1029/2004JD004859, 2004.

Thomason, L. W. and Poole, L. R.: Use of stratospheric aerosol properties as diagnostics of Antarctic vortex processes, J. Geophys. Res., 98, 23003-23012, 1993.

Thomason, L. W. and Taha, G.: SAGE III Aerosol Extinction Measurements: Initial Results, Geophys. Res. Lett., 30, 33-1-33-4, doi:10.1029/2003GL017317, 2003.

Thomason, L. W., Burton, S. P., Iyer, N., Zawodny, J. M., and Anderson, J.: A revised water vapor product for the Stratospheric Aerosol and Gas Experiment (SAGE) II version 6.2 data set, J. Geophys. Res., 109, 6312, doi:10.1029/2003JD004465, 2004.

Thomason, L. W., Poole, L. R., and Randall, C. E.: SAGE III aerosol extinction validation in the Arctic winter: comparisons with SAGE II and POAM III, Atmos. Chem. Phys., 7, 14231433, 2007, http://www.atmos-chem-phys.net/7/1423/2007/.

Thomason, L. W., Burton, S. P., Luo, B.-P., and Peter, T.: SAGE II measurements of stratospheric aerosol properties at non-volcanic levels, Atmos. Chem. Phys., 8, 983-995, 2008, http://www.atmos-chem-phys.net/8/983/2008/.

Wang, H.-J., Cunnold, D. M., Trepte, C., Thomason, L. W., Zawodny J. M.: SAGE III solar ozone measurements: Initial results, Geophys. Res. Lett., 33, L03805, doi:10.1029/2005GL025099, 2006.

Wang, H.-J., Thomason, L. W., Zawodny, J. M.: SAGE III version 4 solar and lunar ozone and $\mathrm{NO}_{2}$ measurements, J. Geophys. Res., submitted, 2009.

WMO (World Meteorological Organization): Scientific Assessment of Ozone Depletion: 2002, Global Ozone Research and Monitoring Project - Report No. 47, 498 pp., Geneva, 2003. 